\title{
Routine biomarkers are strong predictors of short term mortality
}

\author{
Michael Kristensen ${ }^{1 *}$, Charlotte Barfod ${ }^{2}$, Jacob Forberg ${ }^{3}$, György Söletormos ${ }^{4}$, Morten Schou ${ }^{5}$, Kasper Iversen ${ }^{5}$ \\ From 6th Danish Emergency Medicine Conference \\ Odense, Denmark. 20-21 November 2014
}

\section{Background}

Today most patients have a routine biochemical screening taken on arrival to the emergency department. However, the results are not used in the initial assessment of the patients. Including the routine biochemical screening in a triage model may add important predictive value to the initially performed risk stratification.

\section{Methods}

A prospective observational cohort study of 6,279 consecutive patients admitted from the Emergency Department of Hillerød University Hospital. All triaged patients with a full biochemical screening (albumin, creatinine, CRP, haemoglobin, Lactate dehydrogenase, leukocytes, potassium, and sodium) were included. Vital status was collected from the Danish Central Office of Civil Registration. The primary endpoint was 30-day mortality. Secondary endpoints were admission to intensive care unit (ICU) and readmission. Univariate logistic regression splines were made for all eight biomarkers with cuts defined after internationally accepted reference intervals. These models were used to create a multivariate logistic regression spline including all eight biomarkers, and discriminative ability was evaluated with receiver operation characteristics and area under the curve (AUC). Ultimately predicted risks of mortality based on the biomarkers were calculated for all patients, and they were divided into four groups: Green $<1 \%$, yellow $1-10 \%$, orange $10-25 \%$, red $>25 \%$.

\section{Results}

5,371 patients were included (85.5\%). Average age was 60.9 years $[60.6 ; 61.1]$ with $48.0 \%[46.7 ; 49.3 \%]$ males. Overall mortality was $5.3 \%[4.7 ; 5.9 \%]$. Mortality in the

\footnotetext{
* Correspondence: Kristensen.michael@gmail.com

'Department of Cardiology, Nephrology and Endocrinology, Hillerød

University Hospital, Hillerød, Denmark

Full list of author information is available at the end of the article
}

least acute category was $2.8 \%[2.0 ; 3.6 \%]$ for the original triage and significantly lower for the biomarker model, $0.3 \%[0.1 ; 0.5 \%](\mathrm{p}<0.01)$. Mortality in the most acute triage group was $22.6 \%[16.1 ; 29.1 \%]$ and significantly higher for the biomarker model, 43.3\% [37.1; 49.5\%] $(p<0.01)$. Triage was a weak predictor of short-term mortality and demographics (age and sex) alone proved significantly stronger $(\mathrm{AUC}=63.82 \%$ vs. $75.22 \%, \mathrm{p}<$ $0.001)$. Routine biomarkers were strong predictors $($ AUC $=86.41 \%)$ and could improve the original triage significantly $(\triangle \mathrm{AUC}=23.66 \%, \mathrm{p}<0.001)$.

Biomarkers were weak predictors of admission to Intensive Care Units compared to the triage (AUC $=68.66 \%$ vs. 73.15\%), however added to the triage, discrimination was improved significantly $(\triangle \mathrm{AUC}=4.75 \%, \mathrm{p}<0.001)$. None of the models proved able to predict re-admissions.

\section{Conclusion}

Adding biomarkers to the presently used triage model can add significant discriminative value and improve early risk stratification of patients in the emergency department.

\section{Authors' details \\ 'Department of Cardiology, Nephrology and Endocrinology, Hillerød University Hospital, Hillerød, Denmark. ²Department of Anaesthesia, Head and Neck Surgery Centre, University Hospital Rigshospitalet, Copenhagen, Denmark. ${ }^{3}$ Department of Emergency Medicine, Hillerød University Hospital, Hillerød, Denmark. ${ }^{4}$ Department of Clinical Biochemistry, Hillerød University Hospital, Hillerød, Denmark. ${ }^{5}$ Department of Cardiology, Hillerød University Hospital \& Herlev University Hospital, Hillerød, Denmark.}

Published: 16 July 2015

doi:10.1186/1757-7241-23-S1-A55

Cite this article as: Kristensen et al:: Routine biomarkers are strong predictors of short term mortality. Scandinavian Journal of Trauma, Resuscitation and Emergency Medicine 2015 23(Suppl 1):A55.
() Biomed Central

(c) 2015 Kristensen et al. This is an Open Access article distributed under the terms of the Creative Commons Attribution License (http://creativecommons.org/licenses/by/4.0), which permits unrestricted use, distribution, and reproduction in any medium, provided the original work is properly cited. The Creative Commons Public Domain Dedication waiver (http://creativecommons.org/ publicdomain/zero/1.0/) applies to the data made available in this article, unless otherwise stated. 